\title{
Effect of Different Types of Diabetes Mellitus on pregnancy outcomes on Well Controlled Pregnant Women: A cross Sectional Study
}

\author{
Elsayed Hamdi Noureldin* \\ Department of Obstetrics and Gynecology, Zagazig University, Egypt
}

Submission: December 19, 2019; Published: January 07, 2020

*Corresponding author: Elsayed Hamdi Noureldin, Department of Obstetrics and Gynecology, Zagazig University, Egypt

\begin{abstract}
Introduction: Diabetes Mellitus is a metabolic disorder characterized by the presence of hyperglycemia due to defective insulin secretion, defective insulin action or both. It is the most common metabolic disorder that occurs during pregnancy. It has two clinical patterns; either gestational or pregestational diabetes. Pregnancy in women with diabetes mellitus is associated with an increased risk of congenital malformations, obstetric complications and neonatal morbidity. These adverse outcomes are at least in part related to periconceptional care, especially the level of glycemic control. Adequate preconceptional care reduces the frequency of congenital malformations and improves outcome of pregnancy. The current perinatal mortality rates among women who are diabetic remain approximately twice those observed in the non-diabetic population Congenital malformations, respiratory distress syndrome (RDS) and extreme prematurity account for most perinatal deaths in contemporary diabetic pregnancies. The aim of this work to assess the effect of different types of diabetes mellitus without vascular changes on maternal and fetal outcomes.
\end{abstract}

Methods: The study was done at Al Zahraa Hospital, Jeddah. KSA, during the period from September 2017 to September 2019 and included 200 cases of gestational and pregestational diabetic pregnant women. Cases were selected according to the following criteria (pregnant diabetic women at gestational age 28 to 40 weeks, whitout any chronic disease). Verbal consent and full history taking with baseline data were collected during antenatal visits including age, parity and gravdity, past medical history, family history and obstetric history including previous history of gestational diabetes mellitus, previous high birth weight babies (more than4kg), previous unexplained IUFD, previous history of recurrent pregnancy loss. Fasting $\& 2 \mathrm{~h}$ postprandial blood glucose level was done and HbA1c. Complete general and abdominal examination, Obstetric Ultrasonography was done for all patients with Umbilical and middle cerebral artery doppler if needed. Patients were classified into two groups, Gestational diabetes and pregestational diabetes, the two groups were compared according to mode of delivery (normal vaginal delivery or caesarian section),gestational age at delivery, maternal complications, fetal (IUFD and macrosomia) and neonatal(respiratory distress syndrome and birth injuries) complications.

Result: The age of the studied group was (27.5 \pm 7.1$)$ ranged from (19 to 43) years and the BMI of the studied group was (26.5 \pm 4.7$)$ ranged from (19 to 35) and 44\% of PGDM patients was obese. There was no statistically significant difference in positive family history of diabetes and previous history of congenital fetal malformation, Intra Uterine Fetal Death and gestational diabetes mellitus between the two groups. There was no statistically significant difference in gestational age at delivery and mode of delivery in current pregnancy between the two groups. Either diabetes was gestational or pregestational there was no statistical difference between maternal and fetal outcome.

Conclusion: We concluded that either diabetes was gestational or pregestational there was no statistical difference between maternal and fetal outcomes. Optimal control of blood glucose resulted in lower neonatal and maternal complications. Further studies on large geographical scale and larger sample size are required to support our conclusion.

Keywords: Pregestational diabetes; Gestational diabetes; Maternal; Fetal outcomes

Abbreviatations: GDM: Gestational diabetes mellitus; ADA: American Diabetes Assoctiation; GA: Gestational Age; OGTT: Oral Glucose Tolerance Test

\section{Introduction}

Diabetes is disorder in which the body doesn't produce insulin or there is resistance to it. In Type 1 diabetes the body produces little or doesn't produce insulin at all due to auto destruction of
B cells of the pancreas also called (juvenile onset diabetes). In Type 2 diabetes the body doesn't respond to insulin due to insulin resistance also called (adult onset diabetes) [1]. Overt Diabetes 
Mellitus is defined as women with a random plasma glucose level greater than $200 \mathrm{mg} / \mathrm{dl}$ plus classic signs and symptoms such as polydipsia, polyuria and unexplained weight loss or a fasting glucose exceeding $125 \mathrm{mg} / \mathrm{dl}$ are considered by the ADA (American Diabetes Assoctiation-2004) to have overt diabetes [2].

Gestational diabetes mellitus (GDM) is operationally defined as impaired glucose tolerance with onset or first recognition during pregnancy. Its diagnosis is based on single step procedure. In accordance to World Health Organization recommendations, the guideline endorses $2 \mathrm{~h} 75 \mathrm{~g}$ oral glucose tolerance test, irrespective of last meal timings with a cutoff value of $\geq 140 \mathrm{mg} / \mathrm{dL}$ using a plasma standardized glucometer [3].The pre-existing diabetes in pregnancy refers to diabetes diagnosed before pregnancy. The prevalence of pre-existing diabetes has increased in the past decade primarily as a result of the increase in type 2 diabetes. Studies of women with preexisting diabetes show higher rates of complications compared to the general population [4].

Maternal complications of diabetes mellitus include increase in asymptomatic bacteriuria, urinary tract infections, preeclampsia, polyhydramnios which may lead to preterm labor, abruption placenta, postpartum hemorrhage which in turn increases operational delivery. Fetal outcomes include intra uterine fetal death, respiratory distress syndrome, hypoglycemia, congenital malformations and hyperbilirubinaemia [5].

All women of childbearing age with diabetes should be counseled about the importance of tight glycemic control prior to conception. Observational studies show an increased risk of diabetic embryopathy, especially anencephaly, microcephaly, congenital heart disease, and caudal regression, directly proportional to elevations in $\mathrm{HbA1C}$ during the first 10 weeks of pregnancy [6].

Glycemic Targets: (Fasting < 95mg/dL, 1-hour PP (postprandial $<140 \mathrm{mg} / \mathrm{dL}, 2 \mathrm{hr}$ PP <120mg/dL). Fasting and postprandial selfmonitoring of blood glucose are recommended in both GDM and preexisting diabetes in pregnancy to achieve glycemic control. Due to increased red blood cell turnover, HbA1C is slightly lower in normal pregnancy than in normal nonpregnant women. The HbA1C target in pregnancy is $6-6.5 \% ;<6 \%$ may be optimal if this can be achieved without significant hypoglycemia, but the target may be relaxed to $<7 \%$ if necessary, to prevent hypoglycemia [7].

\section{Aim of the Work}

The aim of this work to assess the effect of different types of diabetes mellitus without vascular changes on maternal and fetal outcomes.

\section{Patients and Methods}

This cross-sectional study of pregnant diabetic women attended to antenatal clinic (ANC) and/or admitted to the maternity ward at Al Zahraa Hospital, Jeddah. KSA, during the period from September 2017 to September 2019. Of the 227 diabetic women, 27 cases were excluded from the study due to missing during follow up (11 cases), and 16 cases refused participation. 200 diabetic pregnant women were included in the study and were eligible for the final analysis.

The study protocol was approved by Al Zahraa Hospital Ethical Committee. Counseling of participating women, clear caption of the intervention, and an informed written consent was then taken from all of them. During the ANC visit enrolment, medical, past, surgical and obstetric histories were reviewed, general and abdominal examinations were carried out, FHR was checked, and findings were recorded.

Estimation of gestational age (GA) was done from the date of LMP in women with prior regular periods or estimated from early ultrasound scan (USS) at 7 weeks' gestation. GA was verified by the $13^{\text {th }}$ week USS. Fetal anomaly scan was arranged at around 20 weeks' gestation. Then women were followed up as per the standard pregnancy care for diabetes where they attended every 2 weeks until 28 weeks' gestation, every 1 weeks until 36 weeks' gestation then twice weekly thereafter until delivery. Targeting a fasting glucose level of $60-100 \mathrm{mg} / \mathrm{dl}, 1$-hour postprandial glucose below $120 \mathrm{mg} / \mathrm{dl}$, and glycosylated hemoglobin (HbA1c) below $6.1 \%$ [8]. All women were on insulin therapy.

\section{Inclusion criteria}

a) Pregnant women with pregestational diabetes mellitus (type 1 or type 2 diabetes) without vasculopathy.

b) Pregnant women diagnosed with gestational diabetes mellitus (GDM) by using the 75gm 2-hour oral glucose tolerance test (OGTT).

c) singleton pregnancy.

\section{Exclusion criteria}

a) Women with hypertension, thyroid or connective tissue disorders

b) Multifetal gestations.

c) Uncontrolled diabetics.

d) Abnormal glycosylated hemoglobin (HbA1c) level, above $6.1 \%$.

\section{Cases are divided into two main groups}

a) Group I included 100 pregnant women with pregestational diabetes mellitus (Type 1and Type 2 DM) without vascular changes.

b) Group II included 100 pregnant women with gestational diabetes. GDM was generally diagnosed by OGTT in the second half of pregnancy. The OGTT was performed in the morning after a nightlong fasting from 8 to $12 \mathrm{~h}$. The criteria for diagnosing GDM were at least one abnormally high out of three plasma glucose value measurements during the 75gm OGTT (normal values: 
a fasting level $<92 \mathrm{mg} / \mathrm{dl}$, 1-hour level $<180 \mathrm{mg} / \mathrm{dl}$, 2-hour level $<153 \mathrm{mg} / \mathrm{dl}$ ). The venous blood glucose levels were measured using the glucose oxidase method (Glucose Analyzer; Beckman, Brea, CA). The glucose tolerance was classified by the latest criteria of the International Association of Diabetes in Pregnancy Study Group (IADPSG) [9] by using the 75gm 2-hour oral glucose tolerance test (OGTT) at 24-28week gestation.

\section{Values that indicate gestational diabetes}

a) Fasting: More than or equal to $92 \mathrm{mg} / \mathrm{dL}$.

b) 1-hour: More than or equal to $180 \mathrm{mg} / \mathrm{dL}$.

c) 2-hour: More than or equal to $153 \mathrm{mg} / \mathrm{dL}$.

\section{Fetal investigations}

a) CTG.

b) Trans-abdominal ultrasound examination for fetal viability, gestational age confirmation, measurement of the fetal abdominal circumference (AC), and estimation of expected fetal birth weight (EFBW) Hospital admission of the patients will be at the time of delivery or if developed any complication of diabetes.

\section{Result}

Table 1: Socio-demographic data of the studied groups.

\begin{tabular}{|c|c|c|c|c|c|}
\hline Variable & \multicolumn{2}{|c|}{ pre-GDM N=100 } & \multicolumn{2}{|c|}{ GDM N=100 } & $\mathbf{P}$ \\
\hline \multicolumn{6}{|l|}{ Maternal age (years) } \\
\hline Mean \pm SD & \multicolumn{2}{|c|}{$27.5 \pm 7.1$} & \multicolumn{2}{|c|}{$30.5 \pm 5.4$} & \multirow{2}{*}{0.9} \\
\hline Range & \multicolumn{2}{|c|}{$(19-43)$} & \multicolumn{2}{|c|}{$(19-40)$} & \\
\hline \multicolumn{6}{|l|}{$\mathrm{BMI}(\mathrm{kg} / \mathrm{m} 2)$} \\
\hline Mean \pm SD & \multicolumn{2}{|c|}{$26.5 \pm 4.7$} & \multicolumn{2}{|c|}{$26 \pm 3.8$} & \multirow{2}{*}{0.6} \\
\hline Range & \multicolumn{2}{|c|}{$(18.5-35)$} & \multicolumn{2}{|c|}{$(18.5+33)$} & \\
\hline & No & $\%$ & No & $\%$ & \\
\hline Underweight $<18.5$ & 0 & $0 \%$ & 0 & $0 \%$ & \\
\hline Normal 18.5-24.9 & 36 & $36 \%$ & 44 & $44 \%$ & \\
\hline Overweight 25-29.9 & 20 & $20 \%$ & 24 & $24 \%$ & \\
\hline Obese $>30$ & 44 & $44 \%$ & 32 & $32 \%$ & \\
\hline \multicolumn{6}{|l|}{ Gravidity: } \\
\hline Primigravida & $16 \%$ & & 24 & $24 \%$ & \multirow{2}{*}{0.2} \\
\hline Multigravida & $84 \%$ & & 76 & $76 \%$ & \\
\hline \multicolumn{6}{|l|}{ Parity: } \\
\hline Nulliparous & 10 & $10 \%$ & 5 & $5 \%$ & \multirow{2}{*}{0.4} \\
\hline Multiparous & 90 & $90 \%$ & 95 & $95 \%$ & \\
\hline Abortion & 36 & $36 \%$ & 64 & $64 \%$ & 0.5 \\
\hline Positive Family history of DM & 24 & $24 \%$ & 8 & $8 \%$ & 0.12 \\
\hline \multicolumn{6}{|l|}{ Previous history } \\
\hline GDM & 0 & $0 \%$ & 12 & $12 \%$ & 0.073 \\
\hline CFMF* & 4 & $4 \%$ & 0 & $0 \%$ & 0.314 \\
\hline IUFD** & 4 & $4 \%$ & 0 & $0 \%$ & 0.314 \\
\hline Neonatal death*** & 4 & $4 \%$ & 4 & $4 \%$ & 1 \\
\hline
\end{tabular}

c) Neonatal birth weight is measured in grams upon delivery.

d) Large-for-gestational-age fetuses are defined as those with birth weight above the $90^{\text {th }}$ centile for age, and whose birth weight falling below $10^{\text {th }}$ centile is defined as small-forgestational-age.

e) Mode of delivery will be according to hospital protocol.

\section{Statistical Analysis}

Data were collected from taken history, clinical examination, laboratory investigations, and outcome measured, entered and analyzed using Microsoft Excel software. Then data were submitted to Statistical Package for the Social Sciences software for analysis (SPSS version 20). According to the type of data, qualitative represented as number and percentage, quantitative represented by mean $\pm \mathrm{SD}$, the following tests were used to test the differences for significance; difference and association of qualitative variable by Chi-square test $\left(\mathrm{X}^{2}\right)$, between quantitative parametric groups by t-test, non-parametric by Mann Whitney, correlation by Pearson's correlation and regression. P value was set at $<0.05$ for significant results $\&<0.001$ for high significant result. 
CFMF: cardiac abnormality.

${ }^{* *}$ IUFD: unexplained IUFD.

${ }^{* * *}$ Neonatal death=due to cardiac abnormality and complication of prematurity

$P$-value is non-significant.

Table 2: Comparison between studied groups as regards of mean Fasting, Postprandial blood sugar and HbA1C (N=200).

\begin{tabular}{|c|c|c|c|}
\hline Variable & $\begin{array}{c}\text { Pre-GDM } \\
\mathbf{N = 1 0 0}\end{array}$ & $\begin{array}{c}\text { GDM } \\
\mathbf{N = 1 0 0}\end{array}$ & P Value \\
\hline \multirow{2}{*}{ FBS } & & & \\
\hline Mean \pm SD & $118 \pm 28.9$ & $113 \pm 31.7$ & $0.001^{* *}$ \\
\hline Range & $(80-172)$ & $(90-235)$ & \\
\hline \multirow{2}{*}{ PPBS } & $160.6 \pm 58.1$ & $158.5 \pm 65.6$ & 0.6 \\
\cline { 2 - 4 } & $(95-300)$ & $(98-300)$ & \\
\hline \multirow{2}{*}{ HbA1c } & $6 . \pm 0.9$ & $5.5 .0 \pm 0.98$ & $0.01^{*}$ \\
\hline
\end{tabular}

*Statistically significant difference $(P \leq 0.05)$.

**Statistically highly significant difference $(P \leq 0.001)$.

Table 3: Comparing maternal complications between studied groups $(n=50)$.

\begin{tabular}{|c|c|c|c|c|c|c|c|}
\hline \multirow{2}{*}{ Maternal Complications } & \multicolumn{2}{|c|}{ Total N =200\% } & \multicolumn{2}{|c|}{$\begin{array}{c}\text { Pre-GDM } \\
\text { N=100\% }\end{array}$} & \multicolumn{2}{c|}{ NDM } \\
\hline No complication & 92 & $46 \%$ & 52 & $52 \%$ & 40 & $40 \%$ \\
\hline Gestational HTN & 24 & $12 \%$ & 16 & $16 \%$ & 8 & $8 \%$ \\
\hline PET & 36 & $18 \%$ & 12 & $12 \%$ & 24 & $24 \%$ \\
\hline PROM & 4 & $2 \%$ & 0 & $0 \%$ & 4 & $4 \%$ \\
\hline Preterm labor & 12 & $6 \%$ & 8 & $8 \%$ & $400 \%$ & $44 \%$ \\
\hline Polyhydramnios & 36 & $18 \%$ & 20 & $20 \%$ & 16 & $16 \%$ \\
\hline Oligohydramnios & 16 & $8 \%$ & 12 & $12 \%$ & 4 & $4 \%$ \\
\hline Infection (UTI-candidiasis) & 16 & $8 \%$ & 12 & $12 \%$ & 4 & \\
\hline
\end{tabular}

Table 4: Comparison studied groups as regards fetal outcome.

\begin{tabular}{|c|c|c|c|c|c|}
\hline Fetal Complications & \multicolumn{2}{|c|}{ Pre-GDM N=100 } & \multicolumn{2}{|c|}{ GDM N=100 } & $\mathbf{P}$ \\
\hline Macrosomia $\geq 4 \mathrm{~kg}$ & 24 & $24 \%$ & 12 & $12 \%$ & 0.27 \\
\hline IUFD* & 4 & $4 \%$ & 4 & $4 \%$ & 1 \\
\hline Hypoglycemia & 4 & $4 \%$ & 0 & $0 \%$ & 0.314 \\
\hline Preterm baby & 8 & $8 \%$ & 4 & $4 \%$ & 0.551 \\
\hline $\mathrm{CFMF}^{* *}$ & 4 & $4 \%$ & 0 & $0 \%$ & 0.314 \\
\hline NICU admission & 8 & $8 \%$ & 8 & $8 \%$ & 1 \\
\hline Birth injuries & 0 & $0 \%$ & 0 & $0 \%$ & --- \\
\hline Variables & \multicolumn{2}{|c|}{$\begin{array}{c}\text { Pre-GDM } \\
(n=100)\end{array}$} & \multicolumn{2}{|c|}{$\begin{array}{c}\text { GDM } \\
(n=100)\end{array}$} & $P$ value \\
\hline Neonatal weight (Kg) & \multicolumn{2}{|c|}{$3.2 \pm 0.6$} & \multicolumn{2}{|c|}{$3.6 \pm 0.7$} & 0.5 \\
\hline Apgar score at $1 \mathrm{~min}$ & \multicolumn{2}{|c|}{$8.9 \pm 1.6$} & \multicolumn{2}{|c|}{$9.1 \pm 1.3$} & 0.8 \\
\hline Apgar score at $5 \mathrm{~min}$ & \multicolumn{2}{|c|}{$9.3 \pm 1.7$} & \multicolumn{2}{|c|}{$9.6 \pm 2.1$} & 0.4 \\
\hline Neonatal RDS within $1^{\text {st }}$ hour of delivery & \multicolumn{2}{|c|}{$58.4 \pm 10.1$} & \multicolumn{2}{|c|}{$54.7 \pm 12.8$} & 0.7 \\
\hline
\end{tabular}


Journal of Gynecology and Women's Health

\begin{tabular}{|c|r|c|c|c|}
\hline GA at delivery: & & & & \\
\hline$<37$ weeks & 8 & $8 \%$ & $4 \%$ & $96 \%$ \\
\hline$\geq 37$ weeks & 92 & $92 \%$ & 96 & 0.051 \\
\hline Mode of delivery & & & & \\
\hline CS & 68 & $68 \%$ & 60 & $60 \%$ \\
\hline NVD & 32 & $32 \%$ & 40 & $40 \%$ \\
\hline
\end{tabular}

Table 5: Ultrasound finding among the studied group $(\mathrm{N}=200)$.

\begin{tabular}{|c|c|c|c|c|c|c|c|c|}
\hline Variables & \multicolumn{2}{|c|}{ Total $n=200$} & $\%$ & Pre-GDM & $n=100$ & $\%$ & GDM n & $\%$ \\
\hline Normal & 136 & $68 \%$ & & 56 & $56 \%$ & & 80 & $80 \%$ \\
\hline IUFD & 8 & $4 \%$ & & 4 & $4 \%$ & & 4 & $4 \%$ \\
\hline Polyhydramnios* & 36 & $18 \%$ & & 20 & $20 \%$ & & 16 & $16 \%$ \\
\hline Oligohydramnios** & 16 & $8 \%$ & & 12 & $12 \%$ & & 4 & $4 \%$ \\
\hline Placenta previa & 4 & $2 \%$ & & 4 & $4 \%$ & & 0 & $0 \%$ \\
\hline
\end{tabular}

One woman might have more than one finding.

*polyhydraminous AFI more than $25 \mathrm{~cm}$.

**oligohydraminous AFI less than $5 \mathrm{~cm}$.

This table shows that $(68 \%)$ of the studied group had normal U/S, and (18\%) of them had Polyhydramnios, Oligohydramnios was found in ( $8 \%)$ of them.

The study included 200 pregnant diabetic women attending at Al Zahraa Hospital, Jeddah. KSA, during the period from September 2017 to September 2019,50\% of studied group had pregestational DM and 50\% had gestational DM. The current study revealed that the age of studied groups was $(27.5 \pm 7.1)$ years in PGDM and $(30.5 \pm 5.40)$ years in GDM with no statistically difference in maternal age between two groups. the BMI of studied groups was $(26.5 \pm 4.7)$ ranged from (18.5-35) and 44\% of PGDM and $32 \%$ of GDM patients was obese. The study on the hand revealed that there was no statistically significant difference in positive family history of diabetes and previous history of congenital fetal malformation, Intra Uterine Fetal Death and gestational diabetes mellitus between the two groups that the $84 \%, 76 \%$ of PGDM and GDM groups was multigravida in respectively. The present study revealed that $36 \%$ of PGDM and $64 \%$ of GDM has previous history of abortion (Table 1).

In current study $96 \%$ of GDM group was delivered at gestational age $>37$ weeks and $4 \%$ of them was preterm and as regard mode of delivery $68 \%, 60 \%$ of PGDM and GDM patients respectively delivered by $\mathrm{CS}$. The present study evaluated US findings among participants mothers and found that (72\%) of the studied group had normal U/S, and 14\% of them had Polyhydramnios, Oligohydramnios was found in only (4\%) of them (Table 2). The present study revealed that there was no statistically significant difference in maternal complications between the two groups as gestational hypertension $(52 \% \mathrm{VS}$ $40 \%$ ) respectively, PROM (0 VS 4\%) respectively preterm labor (8\% VS 4\%) respectively, infection ((12\% VS 4\%) respectively polyhydramnios (12\% vs16\%) respectively, and oligohydramnios (8\% VS 4\%) respectively (Table 3).
The current study revealed that there was no statistically significant difference in fetal complications between the two groups. Also there was no statistically significant difference between GDM and pre-GDM groups regarding neonatal weight $(3.2 \pm 0.6)$ and $(3.3 \pm 0.7)$ respectively, Apgar score at $1 \& 5$ minutes $(8.9 \pm 1.6$ and $9.1 \pm 1.3)$ and $(9.3 \pm 1.7$ and $9.6 \pm 2.1)$ respectively and neonatal RDS (58.4 \pm 10.1 and $54,7 . \pm 12.8$ ) respectively (Table $4 \& 5$ ).

\section{Discussion}

The current study revealed that the age of studied groups was (27.5 \pm 7.1$)$ years in PGDM and $(30.5 \pm 5.40)$ years in GDM with no statistically difference in maternal age between two groups. While in Salge et al. [11] the mean age of the women studied was $(28.5 \pm 5.71)$ years. In agreement with the present study, the study of Sugiyamaa et al. [12] found that there was no significant difference in maternal age between the 2 groups. In the present study the BMI of studied groups was $(26.5 \pm 4.7)$ ranged from (18.5-35) and 44\% of PGDM and 32\% of GDM patients was obese.

The study of Soliman et al. [13] assessed BMI and found that Fifty-five percent of DM, 38\% of GDM and $25.6 \%$ of controls were obese $(\mathrm{p}<0.001)$. Pregestational BMI was higher in ODM (Overt diabetes) than in GDM, but gestational weight gain was not significantly different between these groups [12]. Maternal overweight and obesity are associated with multiple congenital malformation and fetal loss (miscarriage, stillbirth, neonatal mortality, and perinatal morbidity). When obesity and diabetes coexist, the risk of malformations is further increased, with different contribution of obesity and hyperglycemia to different anomalies [14]. 
The present study revealed that the $84 \%, 76 \%$ of PGDM and GDM groups was multigravida in respectively.

There was a higher proportion of multigravida than secundigravida and primigravida women $37.1 \%, 17.7 \%$, and $14.5 \%$ respectively) among women with GDM that was in accordance with our study in which $16 \%$ of the studied group were primigravida, (82\%) were multiparous [15]. The present study revealed that was $36 \%$ of PGDM and $64 \%$ of GDM has previous history of abortion. In the study of Shefali et al., 2006, that compared the pregnancy outcomes in mothers with PGDM and GDM. The prevalence of abortions in the GDM group in this study was $2.7 \%$ compared to $10.1 \%$ in the PGDM group showing that PGDM are at increased risk for abortions [16].

In current study $96 \%$ of GDM group was delivered at gestational age $>37$ weeks and $4 \%$ of them was preterm and as regard mode of delivery $68 \%, 60 \%$ of PGDM and GDM patients respectively delivered by CS. In contrast to us, the study of Stogianni et al. [17] among pregnant women with any diabetes type more delivered preterm ( $21 \%$ vs. $6 \%, \mathrm{p}=0.0001)$ and by CS $(30 \%$ vs. $19 \%, p=0.05$ ) compared to those not complicated by diabetes. The mean gestational age at delivery was 37 weeks (38.7 in the control group). Seventy-four (56\%) mothers delivered vaginally (7 required forceps assistance) and 58 (44\%) required cesarean section. In comparison, $22 \%$ of controls underwent cesarean section, twenty-four women underwent emergency cesarean section, and the most common indication was unsatisfactory progress of labor[18]. Soliman et al. [13] revealed that Preterm delivery was significantly higher in women with DM and GDM (13.7\% and 9\%, respectively versus normal women $(6.4 \%)$; $\mathrm{p}<0.001)$. In another study of Shefali et al. [16] found that preterm delivery was 6 (7.6\%) in PGDM and 12 (8.2\%) in GDM. The study on the hand revealed that there was no statistically significant difference in positive family history of diabetes and previous history of congenital fetal malformation, Intra Uterine Fetal Death and gestational diabetes mellitus between the two groups.

In agreement with us, another study of Macintosh et al. [19] revealed that statistically significant increases were confined to anomalies of the nervous system (prevalence ratio 2.7, 1.5 to 4.4; $\mathrm{P}<0.001$ ) and congenital heart disease (prevalence ratio 3.4, 2.5 to 4.6; $\mathrm{P}<0.001)$.The prevalence of major congenital anomaly was $46 / 1000$ births in women with diabetes (48/1000 births for type 1 diabetes; 43/1000 for type 2 diabetes), more than double that expected. This increase was driven by anomalies of the nervous system, notably neural tube defects (4.2-fold), and congenital heart disease (3.4-fold). Anomalies in 71/109 (65\%) offspring were diagnosed antenatally.

Women with history of GDM are at an increased risk of adverse maternal and perinatal outcome and at increased risk of future diabetes predominantly Type II including their children and therefore there are two generations at risk [20]. The present study evaluated US findings among participants mothers and found that (72\%) of the studied group had normal U/S, and 14\% of them had Polyhydramnios, Oligohydramnios was found in only (4\%) of them.

Poorly managed gestational diabetes is associated with fetal macrosomia and polyhydramnios, but the pathogenesis has not been elucidated yet [21]. The present study revealed that there was no statistically significant difference in maternal complications between the two groups as gestational hypertension, PROM, preterm labor. Any degree of glucose intolerance during pregnancy is associated with adverse maternal and fetal outcome. The adverse maternal complications include hypertension, preeclampsia, urinary tract infection, hydramnios, increased operative intervention and future DM [22].

Another study of Soliman et al. [13] revealed that Pregnant women with DM or GDM had higher prevalence of hypertension versus normal controls $(9.9 \%, 5.5 \%$ and $3.5 \%$, respectively; $\mathrm{p}<0.001$ ). Twenty-four women underwent emergency cesarean section, and the most common indication was unsatisfactory progress of labor. Thirty-four percent of the women had complications either during pregnancy or labor and all complications were significantly less in the control group. The maternal complications were more common in mothers with less than optimal control ( $41 \%$ vs. $30 \%$ ), but this was not statistically significant $(\mathrm{P}=0.26)$. GDM is associated with an increased risk of complications for both the mother and the child. The rate of preeclampsia and cesarean section is increased in the mother and the risk of macrosomia is increased in the newborn [18].

The current study revealed that there was no statistically significant difference in fetal complications between the two groups. In agreement with our study, the study of Sugiyamaa et al. [12] found that no significant differences in neonatal outcomes were observed between the GDM and ODM groups. LGA infants are a well-recognized and significant complication of GDM. Other studies have also demonstrated higher rates of abnormalities in pregnancy outcomes in PGDM compared to GDM [23]. Also Stogianni et al. [17] assessed Frequency of LGA among all mothers, with and without diabetes, was $21.6 \%(60 / 278)$ and among those without diabetes $17.0 \%(23 / 135)$. Within the PDM group, a higher number of infants in the T1DM group were LGA, $60 \%(22 / 37)$ vs. $27 \%$ (3/11) among T2DM, the difference did not reach significance $(\mathrm{p}=0.15)$. Only two children, in the PDM group, $4.3 \%$ (2/48), were macrosomic at birth.

Studies of women with preexisting diabetes show higher rates of complications compared to the general population, including perinatal mortality, congenital malformations, hypertension, preterm delivery, large-for-gestational age infants, caesarean delivery and other neonatal morbidities [19]. The present study revealed that there was no statistically significant difference between GDM and pre-GDM groups regarding neonatal weight, Apgar score at $1 \& 5$ minutes and neonatal RBS. In the previous study of Owens et al. found that there was no difference in mean 
birth weight between groups (3.54kg) and controls. There was an increase in babies born $>4 \mathrm{~kg}$ to women with T1DM compared to matched controls. Neonatal hypoglycemia was more prevalent in offspring of both T1 DM and T2 DM pregnancies when compared to matched-controls and higher in offspring of T1DM than T2DM. Hypocalcemia, neonatal jaundice, shoulder dystocia and polycythemia were similar between groups and matched controls. These however are relatively rare outcomes and the numbers in this study are too small to detect significant differences in these outcomes. The stillbirth rate was higher in babies of T1DM mothers compared to controls, but no difference was seen in mothers with T2 DM [24].

Of note, babies born to women with diabetes have significantly higher rates of being large for gestational age (LGA) (birth weight $>90$ th percentile for gestational age and sex), macrosomia (birth weight $>4,000 \mathrm{~g}$ or $8 \mathrm{lb} 13 \mathrm{oz}$ ), and neonatal hypoglycemia [23]. In the study of Prakash et al., 2017, the deaths occurred in neonates with birth weight which was less than average for gestational age [18]. Similar in the study by Sreelakshmi et al. [25] Respiratory distress was more common in neonates with above average birth weight. It was less in neonates born to mothers with optimal BS control. However, this was not an expected finding.

Respiratory distress was noted more commonly in the intervention arm of the trial done by Crowther et al. [26] It is interesting to note that a recent retrospective review has found that neonatal respiratory distress syndrome was more common in insulin-treated mothers with any form of diabetes. Neonatal hypoglycemia occurred in six newborns (4\%) in this study. All episodes occurred in newborns whose mothers had suboptimal blood sugar control before delivery.

Serious perinatal complications specifically attributable to gestational diabetes are in general rare [27]. The present study assessed Laboratory investigations of the studied group and found that the fasting blood glucose ranged from 80 to 235 , HbA1C ranged from 5.3 to 9.5 and PPBS ranged from 95 to 300 . Women with PGDM had significantly higher fasting plasma glucose $[\mathrm{p}<0.001]$ levels compared to GDM [16].

In agreement with our study, the study of Owens et al. [24] found that overall the mean HbA1C in pregnancy is lower in women with $\mathrm{T} 2$ compared to T1 DM (5.8 vs. $6.6 \%, \mathrm{p}=0.001$ ). In each trimester and prior to delivery mean $\mathrm{HbA} 1 \mathrm{C}$ is also significantly lower in women with T2 compared to T1 DM and in both groups $\mathrm{HbA} 1 \mathrm{C}$ improves as pregnancy progresses reaching a nadir of $6.4 \%$ and $5.7 \%$ in women with $\mathrm{T} 1$ and $\mathrm{T} 2 \mathrm{DM}$ respectively at term.

In contrast to us, the study of Macintosh et al. [19] most women (1606; 68\%) had a recorded measurement of glycaemic control by 13 weeks of pregnancy. Good control, defined by (HbA1c) of less than $7 \%$, was achieved by 596 (37\%) women. The median HbA1c was $7.9 \%$ for the women whose pregnancies resulted in a congenital anomaly, 8.0\% for those with a normally formed stillbirth or neonatal. Diabetes during pregnancy is an increasingly common metabolic disorder, associated with significantly increased risks for both mother and child, Pregnancies complicated by diabetes are associated with significantly increased risks for both mother and child [17].

Improvement in the diagnosis and management of pregnant women with dysglycemia lead to marked improvement in the neonatal outcome with a reduction in the rate of macrosomia, hypoglycemia, NICU admission and congenital malformations. However, there is still a higher prevalence of these comorbidities in infants of DM and GDM compared to normal women. Obesity and overweight in women during the childbearing period appear to contribute to the occurrence of high rates of dysglycemia during pregnancy. Measurements to reduce obesity during the childbearing period and accurate glucose control during pregnancy are highly required to prevent any morbidity during pregnancy of women with DM and GDM [13].

\section{Conclusion}

Despite the improvement in the prenatal diagnosis and management of dysglycemia, there is still a higher prevalence of prematurity, macrosomia, and other fetal and maternal complications. Measurements to reduce obesity and control dysglycemia in women during the childbearing period are highly required to prevent the still higher morbidity during pregnancy.

\section{References}

1. Sacks D, Berger H, Murphy TG (2011) Diabetes and pregnancy. Pp. 8-11.

2. Das A (2017) Maternal and perinatal outcomes in diabetic pregnancies at BPKIHS. Int J Reprod Contracept Obstet Gynecol 6(6): 22622266.

3. Mishra S, Bhadoria AS, Kishore S, Kumar R (2018) Gestational diabetes mellitus 2018 guidelines: An update. J Family Med Prim Care $7(6): 1169-1172$.

4. Feig D, Berger H, Donovan L, Godbout A, Kader T, et al. (2018) Diabetes and Pregnancy. Can J Diabetes 42(Suppl 1): S255-S282.

5. Shukla A, Burute Sh, Meena A (2017) Maternal and fetal outcome in gestational diabetes-A retrospective study. International Journal of Applied Research 3(9): 305-309.

6. American Diabetes Assoctiation (2019) Management of Diabetes in Pregnancy: Standards of Medical Care in Diabetes-2019. Diabetes Care 42 (Suppl 1): S165-S172.

7. American Diabetes Assoctiation (2018) Management of Diabetes in Pregnancy: Standards of Medical Care in Diabetes - 2018. Diabetes Care 41 (Suppl.1): S137-S143.

8. Yang YD, Zhai GR, Yang HX (2010) Factors relevant to Newborn birth weight in pregnancy complicated with abnormal glucose metabolism. Zhonghua Fu Chan Ke Za Zhi 45(9): 646-651.

9. International Association of Diabetes and Pregnancy Study Groups (2010) Recommendations on the diagnosis and classification of hyperglycemia in pregnancy. Diabetes Care 33(3): 676-682.

10. Rani PR, Begum J (2016) Screening and diagnosis of gestational diabetes mellitus, where do we stand. J Clin Diagn Res 10(4): QE01QE04. 
11. Salge AK, Rocha KM, Xavier RM, Ramalho WS, Rocha ÉL, et al. (2012) Macroscopic placental changes associated with fetal and maternal events in diabetes mellitus. Clinics 67(10): 1203-1208.

12. Sugiyamaa T, Saitoa M, Nishigoria H, Nagasea S, Yaegashia N, et al. (2013) Comparison of pregnancy outcomes between women with gestational diabetes and overt diabetes first diagnosed in pregnancy: A retrospective multi-institutional study in Japan. Diabetes Res Clin Pract 103(1): 20-25.

13. Soliman A, Husam Salama, Hilal Al Rifai, Vincenzo De Sanctis, Sawsan Al-Obaidly, et al. (2018) The effect of different forms of dysglycemia during pregnancy on maternal and fetal outcomes in treated women and comparison with large cohort studies. Acta Biomed 89(Suppl 5): 11-21.

14. Martínez-Frías ML, Frías JP, Bermejo E, Rodríguez-Pinilla E, Prieto L, et al. (2005) Pre-gestational maternal body mass index predicts an increased risk of congenital malformations in infants of mothers with gestational diabetes. Diabet Med 22(6): 775-781.

15. Stanley K, Fraser R, Bruce C (1998) Physiological changes in insulin resistance in human pregnancy: Longitudinal study with the hyperinsulinaemic euglycaemic clamp technique. Br J Obstet Gynaecol 105(7): 756-759.

16. Shefali AK, Kavitha M, Deepa R, Mohan V (2006) Pregnancy outcomes in pre-gestational and gestational diabetic women in comparison to non-diabetic women-A prospective study in Asian Indian mothers (CURES-35). J Assoc Physicians India 54(8): 613-618.

17. Stogianni A, Lendahls L, Landin-Olsson M, Thunander M (2019) Obstetric and perinatal outcomes in pregnancies complicated by diabetes, and control pregnancies, in Kronoberg, Sweden. BMC pregnancy and childbirth 19(1): 159.

18. Prakash GT, Das AK, Habeebullah S, Bhat V, Shamanna SB, et al. (2017) Maternal and Neonatal Outcome in Mothers with Gestational Diabetes Mellitus. Indian J Endocrinol Metab 21(6): 854-858.
19. Macintosh MC, Fleming KM, Bailey JA, Doyle P, Modder J, et al. (2006) Perinatal mortality and congenital anomalies in babies of women with type 1 or type 2 diabetes in England, Wales, and Northern Ireland: Population based study. BMJ 333(7560): 177.

20. Rani PR, Begum J (2016) Screening and Diagnosis of Gestational Diabetes Mellitus, Where Do We Stand. Journal of clinical and diagnostic research. J Clin Diagn Res 10(4): QE01-QE4.

21. Vink JY, Poggi SH, Ghidini A, Spong CY (2006) Amniotic fluid index and birth weight: is there a relationship in diabetics with poor glycemic control? Am J Obstet Gynecol 195(3): 848.

22. Casey BM, Lucas MI, Mcintire DD, Liezemo KJ (1997) Pregnancy outcomes in women with GDM compared with the genetic obstetric population. Obstet Gynecol 90(6): 869-873.

23. Evers IM, deValk HW, Mol BW, TBraak EW, Visser GH, et al. (2002) Macrosomia despite good glycaemic control in Type I diabetic pregnancy; results of a nationwide study in The Netherlands. Diabetologia 45(11):1484-1489.

24. Owens LA, Sedar J, Carmody L, Dunne F (2015) Comparing type 1 and type 2 diabetes in pregnancy- similar conditions or is a separate approach required? BMC pregnancy and childbirth15: 69.

25. Sreelakshmi PR, Nair S, Soman B, Alex R, Vijayakumar K, et al. (2015) Maternal and neonatal outcomes of gestational diabetes: A retrospective cohort study from Southern India. J Family Med Prim Care 4(3): 395-398.

26. Crowther CA, Hiller JE, Moss JR, McPhee AJ, Jeffries WS, et al. (2005) Australian Carbohydrate Intolerance Study in Pregnant Women (ACHOIS) Trial Group. Effect of treatment of gestational diabetes mellitus on pregnancy outcomes. N Engl J Med 352(24): 2477-2486.

27. Mitanchez D (2010) Foetal and neonatal complications in gestational diabetes: Perinatal mortality, congenital malformations, macrosomia, shoulder dystocia, birth injuries, neonatal complications. Diabetes Metab 36(6 Pt 2): 617-627.

\section{Your next submission with Juniper Publishers will reach you the below assets}

- Quality Editorial service

- Swift Peer Review

- Reprints availability

- E-prints Service

- Manuscript Podcast for convenient understanding

- Global attainment for your research

- Manuscript accessibility in different formats

( Pdf, E-pub, Full Tsext, Audio)

- Unceasing customer service

Track the below URL for one-step submission https://juniperpublishers.com/online-submission.php 